\title{
Infección del orificio de salida y anillo externo del catéter peritoneal tratada mediante técnica de Friedrich
}

\author{
Lourdes Picó Mira, Luis Picó Vicent, Leonor Blaya Ruiz, Ma Isabel Hernández Martínez, Rosa Mª Serrano \\ Borrell, Ángeles Lillo Gisbert
}

Hospital General Universitario. Alicante

\section{Introducción:}

Ante una infección crónica del orificio de salida y del dacron externo del catéter peritoneal, las alternativas son retirar el catéter o exteriorizar el anillo de Dacron mediante técnica de Friedrich, con resección y limpieza de los tejidos anormales $(1,2,3,4,5,6)$.

\section{Objetivo:}

Exponer la evolución de una infección del orificio de salida del catéter, resistente a diversos tratamientos, finalmente resuelta con la aplicación de ésta técnica.

\section{Material y metodo:}

Paciente varón de 39 años con insuficiencia renal crónica por nefropatía IgA. Se implantó catéter peritoneal autoposicionante el 25/09/12. Inicio de DPCA el 05/11/12. 07/01/13 consulta por orificio "irritado", objetivandose infección. Tejido inflamatorio, granuloma, exudado serohemático y sangrado fácil a la manipulación. El anillo externo se encuentra colocado sobre el orificio, presionando la piel hacia el exterior.

Tratamiento local: TOBRAMICINA gotas.

Cultivo: ESTAFILOCOCO AUREUS Meticilín Sensible (MS) sensible a Tobramicina, parcialmente sensible a quinolonas. 11/01/13 Orificio con supuración, aunque con mejor aspecto. Igual tratamiento local.

Tratamiento oral: CLOXACILINA 1g.c/8h. 23/01/13 Orificio con peor aspecto. Supurativo, sanguinolento y tejido macerado alrededor. Se administra VANCOMICINA 1g.i.v. desarrollando rash alérgico. Mismo trata- miento tópico y oral a la espera de resolución del rash. 01/02/13 sigue tejido macerado y sangrado a la manipulación. Se mantiene tratamiento tópico, suspendiendo Cloxacilina. Se inicia CEFAZOLINA intraperitoneal, lgr/día (bolsa nocturna).

Nuevo cultivo: Estafilococo Aureus MS con el mismo antibiograma. 07/02/13 sigue con supuración, sangrado y granuloma. Ingresa para tratamiento con CLOXACILINA iv, 2gr/6h. Igual tratamiento tópico. Sin mejoría. 12/02/13 se sustituye Cloxacilina por DAPTOMICINA iv. Sin mejoría. Ante mala evolución se decide actuación quirúrgica. 21/02/13 se realiza cirugía sobre el orificio (FRIEDRICH). Liberalización y externalización del anillo externo. Exéresis del tejido infectado hasta llegar a tejido sano creando un nuevo orificio de salida. Se deja herida abierta para cicatrización por segunda intención. Tras la cirugía se administró DAPTOMICINA intraperitoneal + NOLOTIL iv. Aparición de rash pápulo-eritematoso pruriginoso generalizado. Se sustituyó Daptomicina por CEFAZOLINA intraperitoneal lgr/día, 15 días (bolsa nocturna) No se usó más Nolotil. 22/02/13 se dan dos puntos de aproximación. Se pela el anillo extrusado. Cura del orificio y herida, dejando gasa con betadine, cada dos días. 11/03/13 granulación buena pero lenta. Se sustituyen las curas con gasa+betadine por apósito adaptable de hidrogel INTRASITE CONFORMABLE cada 3-4 días. 15/03/13 se quitan los puntos de sutura. 23/03/13 buena evolución del orificio y herida. Se aproximan bordes con STERISTRIP. 02/04/13 herida prácticamente cerrada. Orificio y herida con buena coloración y limpios. Curas locales diarias con MUPIROCINA pomada. 05/04/13. herida cerrada. Buena coloración de la piel. Orificio con buen aspecto. Igual tratamiento tópico. 26/04/13. herida con buena cicatrización. Orificio sin signos anormales, buen estado del seno y color de la piel. Igual tratamiento. 


\section{Conclusiones:}

La realización de la técnica de Friedrich para intentar salvar el catéter peritoneal ante una infección crónificada de orificio y anillo externo por Estafilococo Aureus no es una práctica frecuente, pero en el caso que nos ocupa resolvió un problema que presentaba mala evolución con el tratamiento habitual.

\section{Referencias Bibliográficas}

1. M $M^{a}$ J. Vega García, C. Sánchez Fonseca, $M^{a}$ C. García Rodríguez, C. Felipe Fernández, R. Manzanedo Bueno. Estudio de la extrusión del dacron externo del catéter de diálisis peritoneal Enfermería Nefrológica. Volumen 15, Suplemento 1, Pag. 146147, 2012.

2. A. Concepción Gómez Castilla, Ma del C. Páez Antunez, $M^{a}$ Á. Ojeda Guerrero, N. Aresté Fonsalba, Miguel Á. Ramírez López, D. Fernández Gordillo.
La extrusión del dacron subcutáneo como tratamiento de la infección crónica del orificio de salida del catéter de diálisis peritoneal. Enfermería Nefrológica. No 4, Volumen 14, Pag. 276, IV Trimestre 2011.

3. S. Sánchez de la Torre Complicaciones mecánicas de la Diálisis Peritoneal. Manual práctico de Diálisis Peritoneal. F. Coronel et al.1-2005 Cap.41, Pag. 335-343.

4. N. E. Caporale González, M ${ }^{\mathrm{a}}$ C. Verocay Mulell, D. Pérez Escursell. Complicaciones del orificio de salida del catéter y del túnel. La Diálisis Peritoneal. Montenegro J., Olivares J. Pag. 291-305, 1999.

5. A. Granado Lezcano, M. Cobanera Altuna, L. Tovar Echevarría, J. M. Mayor Iturburuaga. Exéresis del dacron externo en las infecciones crónicas del orificio de salida del cateter Comunicación presentada al XIX Congreso Nacional de la SEDEN.

6. J. Montenegro. Prevención y tratamiento de la infección del orificio de salida del catéter peritoneal. Nefrología. Vol. XIX, nº 6, Pag. 502-507, 1999. 